\title{
PEMILIHAN PERUMAHAN TERFAVORIT MENGGUNAKAN METODE VIKOR DAN TOPSIS DENGAN GUI MATLAB (Studi Kasus: Perumahan Mijen Semarang)
}

\author{
Alika Ramadhani ${ }^{1}$, Rukun Santoso ${ }^{2}$, Rita Rahmawati ${ }^{3}$ \\ 1,2,3 Departemen Statistika FSM Universitas Diponegoro \\ rukunsantoso25@gmail.com
}

\begin{abstract}
The increase in the population of Semarang has an impact on the increasing demand for residential housing. Unfortunately, the limitations of the area became an obstacle in Semarang to develop residential areas. This development of residential housing in Semarang leads to suburban such as Mijen. The method that can be used to choose favorite housing is Visekriterijumsko Kompromisno Rangiranje (VIKOR) and Technique for Order Preference by Similarity to Ideal Solution (TOPSIS). Both methods can be applied to solve Multiple Criteria Decision Making (MCDM) issue. This study has 8 alternatives of residential housing in Mijen with 5 criteria such as Price, Payment Method, Building Specifications, Housing Facilities, and Location. This research was design with Graphical User Interface (GUI) Matrix Laboratory (MATLAB) as computing tool. VIKOR and TOPSIS method on this research, obtained the same result that the most favorite residential housing is $A_{5}$.
\end{abstract}

Keywords: Housing, SPK, VIKOR, TOPSIS, GUI

\section{PENDAHULUAN}

Tempat tinggal atau yang biasa disebut rumah merupakan salah satu kebutuhan pokok manusia selain pakaian dan makanan. Seiring berjalannya waktu, pertumbuhan penduduk di Indonesia setiap tahunnya selalu bertambah, termasuk di Kota Semarang. Meningkatnya penduduk Kota Semarang berdampak pada meningkatnya pula kebutuhan rumah huninan, hal tersebut terkendala dengan keterbatasan lahan yang berada di sekitar kota untuk dikembangkan sebagai lahan perumahan, sehingga pengembangan perumahan di Kota Semarang mengarah ke daerah pinggiran kota, seperti wilayah Mijen.

Menyadari hal tersebut para developer perumahan bersaing ketat dalam mencari perhatian konsumen untuk memilih produk mereka. Para developer perumahan banyak menawarkan berbagai kemudahahan mulai dari harga, lokasi perumahan, desain, fasilitas penunjang dan berbagai kemudahan lainnya. Sehingga tak jarang para konsumen menjadi bingung dalam hal menentukan hunian yang pas untuk mereka tempati.

Salah satu upaya untuk membantu konsumen dalam memilih perumahan sesuai dengan spesifikasi dan anggaran yang dimiliki adalah dengan merancang suatu sistem pendukung keputusan. SPK berguna untuk mengatasi permasalahan yang dihadapi sehingga mendapatkan solusi yang tepat bagi tiap alternatifnya. Dengan adanya SPK diharapkan dapat mempermudah konsumen dalam memilih tempat tinggal sesuai kebutuhan dan anggaran.

Metode Multiple Criteria Decision Making (MCDM) merupakan suatu metode pengambilan keputusan untuk menetapkan alternatif terbaik dari sejumlah alternatif berdasarkan beberapa kriteria tertentu. Terdapat beberapa metode yang dapat digunakan untuk menyelesaikan masalah MCDM diantaranya adalah metode VIKOR dan TOPSIS. Sedangkan GUI Matlab digunakan sebagai alat komputasi untuk melakukan pengambilan keputusannya. 


\section{TINJAUAN PUSTAKA}

\subsection{Pengertia Rumah}

Dalam Undang-Undang Republik Indonesia tentang Perumahan dan Kawasan Pemukiman Nomor. 1, 2011, rumah adalah bangunan gedung yang berfungsi sebagai tempat tinggal yang layak huni, sarana pembinaan keluarga, cerminan harkat dan martabat penghuninya, serta aset bagi pemiliknya. Menurut Mukono (2000), fungsi rumah adalah tempat berlindung agar tetap aman dan terhindar dari gangguan alam/cuaca maupun hewan buas. Untuk menyimpan barang berharga dan sebagai lambang status sosial, serta merupakan tempat untuk melepas lelah setelah seharian beraktivitas.

\subsection{Pengertian Perumahan}

Berdasarkan Undang-Undang Republik Indonesia tentang Perumahan dan Kawasan Pemukiman Nomor. 1, 2011, perumahan adalah kelompok rumah yang berfungsi sebagai lingkungan tempat tinggal atau lingkungan hunian yang dilengkapi dengan sarana dan prasarana lingkungan. Prasarana lingkungan berupa kelengkapan fasilitas dasar yang memungkinkan perumahan dapat berfungsi sebagaimana mestinya dalam mewujudkan lingkungan yang sehat, aman dan teratur. Sedangkan sarana lingkungan berupa fasilitas yang dapat digunakan sebagai pendukung kegiatan penghuni perumahan baik aspek ekonomi, sosial maupun budaya yang berfungsi sesuai yang diharapkan.

\subsection{Sistem Pendukung Keputusan (SPK)}

Menurut Turban (1990), menyebutkan bahwa konsep sistem pendukung keputusan (SPK) sebagai sistem interaktif berbasis komputer yang dapat membantu seseorang dalam mengambil keputusan. SPK berguna untuk dapat mengatasi permasalahan yang dihadapi sehingga mendapatkan solusi yang tepat bagi tiap alternatifnya.

\subsection{Metode Multiple Criteria Decision Making (MCDM)}

Menurut Kusumadewi dkk. (2006) MCDM adalah suatu metode pengambilan keputusan untuk menetapkan alternatif terbaik dari sejumlah alternatif berdasarkan beberapa kriteria tertentu. Tujuan MCDM adalah mengevaluasi m alternatif $A_{i}(\mathrm{i}=1,2, \ldots, \mathrm{m})$ terhadap sekumpulan kriteria $C_{j}(\mathrm{j}=1,2, \ldots, \mathrm{n})$. Matriks keputusan setiap alternatif terhadap setiap kriteria diberikan sebagai berikut:

$$
\mathbf{X}=\left[\begin{array}{cccc}
x_{11} & x_{12} & \ldots & x_{1 n} \\
x_{21} & x_{22} & \ldots & x_{2 n} \\
\ldots & \ldots & \ldots & \ldots \\
x_{m 1} & x_{m 2} & \ldots & x_{m n}
\end{array}\right]
$$

Nilai bobot yang menunjukkan tingkat kepentingan relatif setiap kriteria adalah sebagai berikut:

$$
\begin{aligned}
& \mathbf{w}=\left\{w_{1}, w_{2}, \ldots, w_{n}\right\} \\
& w_{j}=\frac{u_{j}}{\sum_{j=1}^{n} u_{j}}
\end{aligned}
$$

dengan,

$$
\begin{aligned}
& u_{j}=\frac{1}{l} \sum_{k=1}^{l} z_{k j} \\
& \sum_{j=1}^{n} w_{j}=1
\end{aligned}
$$


Keterangan:

$w_{j}=$ nilai bobot kriteria ke- $\mathrm{j}, \mathrm{j}=1,2, \ldots, \mathrm{n}$

$u_{j}=$ rata-rata penilaian responden terhadap bobot kriteria ke-j

$z_{k j}=$ nilai bobot kriteria ke-j oleh responden ke-k, $\mathrm{k}=1,2, \ldots, l$

$l=$ banyaknya sampel

\subsection{Metode Visekriterijumsko Kompromisno Rangiranje (VIKOR)}

Metode VIKOR merupakan salah satu metode MCDM yang memiliki prosedur perhitungan sederhana dengan pertimbangan kedekatan antar alternatif dengan solusi ideal. Metode ini dibangun untuk optimasi multikriteria pada sistem yang kompleks (Opricovic dan Tzeng, 2004).

Langkah-langkah yang digunakan dalam metode VIKOR adalah sebagai berikut:

1. Membuat matriks keputusan $(\mathbf{X})$ seperti pada Persamaan (1)

2. Menentukan nilai bobot $\left(w_{j}\right)$ seperti pada Persamaan (3)

3. Melakukan normalisasi elemen $x_{i j}$ dalam matriks keputusan $(\mathbf{X})$, dengan persamaan sebagai berikut:

$N_{i j}=\frac{\left(f_{j}^{+}-x_{i j}\right)}{\left(f_{j}^{+}-f_{j}^{-}\right)}$

Keterangan:

$f_{j}^{+} \quad$ : Nilai terbaik/positif dalam kriteria ke-j

$f_{j}^{-} \quad$ : Nilai terjelek/negatif dalam kriteria ke-j

$N_{i j}$ : Elemen matriks ternormalisasi

Menentukan nilai positif ideal $\left(f_{j}^{+}\right)$dan negatif ideal $\left(f_{j}^{-}\right)$sebagai solusi ideal, dengan rumus:

$f_{j}^{+}=\operatorname{Max}_{i}\left(x_{i j}\right) ;$ jika j merupakan kriteria keuntungan (benefit)

$f_{j}^{-}=\operatorname{Min}_{i}\left(x_{i j}\right)$

atau,

$f_{j}^{+}=\operatorname{Min}_{i}\left(x_{i j}\right) ;$ jika j merupakan kriteria biaya $($ cost $)$

$f_{j}^{-}=\operatorname{Max}_{i}\left(x_{i j}\right)$

5. Membuat matriks ternormalisasi terbobot $(\boldsymbol{F})$, dengan perhitungan sebagai berikut:

$F_{i j}=w_{j} \times N_{i j}$

6. Menghitung Utility Measures

Utility measures dari setiap alternatif dihitung menggunakan rumus sebagai berikut:

$S_{i}=\sum_{j=1}^{n} w_{j} \frac{\left(f_{j}^{+}-x_{i j}\right)}{\left(f_{j}^{+}-f_{j}^{-}\right)}$

$R_{i}=\operatorname{Max}_{j}\left[w_{j} \frac{\left(f_{j}^{+}-x_{i j}\right)}{\left(f_{j}^{+}-f_{j}^{-}\right)}\right]$

Perangkingan $S_{i}$ (maximum group utility) merupakan perangkingan berdasarkan pendekatan dengan solusi terjauh dengan solusi ideal, perangkingan $R_{i}$ (minimum individual regret of the opponent) adalah perangkingan berdasarkan pendekatan dengan solusi terdekat dengan solusi ideal, sedangkan $w_{j}$ adalah bobot yang diberikan pada setiap kriteria ke-j. 
7. $\quad$ Menghitung indeks VIKOR $(\boldsymbol{Q})$

Setiap alternatif i dihitung indeks VIKOR-nya menggunakan rumus sebagai berikut:

$Q_{i}=v\left[\frac{S_{i}-S^{-}}{S^{+}-S^{-}}\right]+(1-v)\left[\frac{R_{i}-R^{-}}{R^{+}-R^{-}}\right]$

dengan,

$S^{-}=\operatorname{Min}\left(S_{i}\right)$

$S^{+}=\operatorname{Max}\left(S_{i}\right)$

$R^{-}=\operatorname{Min}\left(R_{i}\right)$

$R^{+}=\operatorname{Max}_{i}\left(R_{i}\right)$

$v$ merupakan nilai bobot strategis berkisar antara 0-1, dengan niai $v$ diasumsikan 0,5.

Nilai $Q_{i}$ terkecil mengindikasikan bahwa alternatif $A_{i}$ merupakan alternatif terbaik.

\subsection{Metode Technique for Order Preference by Similarity to Ideal Solution (TOPSIS)}

Metode TOPSIS didasarkan pada konsep dimana alternatif terpilih yang terbaik tidak hanya memiliki jarak terpendek dari solusi ideal positif, namun juga memiliki jarak terpanjang dari solusi ideal negatif (Kusumadewi, 2006).

Langkah-langkah yang digunakan dalam metode TOPSIS adalah sebagai berikut:

1. Membuat matriks keputusan (X) seperti pada Persamaan (1)

2. Menentukan nilai bobot $\left(w_{j}\right)$ seperti pada Persamaan (3)

3. Melakukan Normalisasi Matriks Keputusan

Melakukan normalisasi elemen $x_{i j}(\mathrm{i}=1,2, \ldots, \mathrm{m})$ dalam matriks keputusan $(\mathbf{X})$ dengan persamaan sebagai berikut:

$p_{i j}=\frac{x_{i j}}{\sqrt{\sum_{j=1}^{n} x_{i j}^{2}}}$

4. Membuat Matriks Ternormalisasi Terbobot, dengan perhitungan sebagai berikut:

$y_{i j}=w_{j} \times p_{i j}$

5. Menentukan Matriks Solusi Ideal (A)

$A^{+}=\left(y_{1}^{+}, y_{2}^{+}, \ldots, y_{n}^{+}\right)$

$A^{-}=\left(y_{1}^{-}, y_{2}^{-}, \ldots, y_{n}^{-}\right)$

dengan,

$y_{j}^{+}=\operatorname{Max}_{i}\left(y_{i j}\right) ;$ jika j merupakan kriteria keuntungan (benefit)

$y_{j}^{-}=\operatorname{Min}\left(y_{i j}\right)$

atau,

$y_{j}^{+}=\operatorname{Min}_{i}\left(y_{i j}\right)$

$y_{j}^{-}=\operatorname{Max}\left(y_{i j}\right)$

jika j merupakan kriteria biaya (cost)

6. Menentukan Jarak Matriks Solusi Ideal (D)

Jarak antara alternatif $A_{i}$ dengan solusi ideal positif dirumuskan sebagai berikut:

$D_{i}^{+}=\sqrt{\sum_{j=1}^{n}\left(y_{j}^{+}-y_{i j}\right)^{2}}$

Jarak antara alternatif $A_{i}$ dengan solusi ideal negatif dirumuskan sebagai berikut:

$D_{i}^{-}=\sqrt{\sum_{j=1}^{n}\left(y_{i j}-y_{j}^{-}\right)^{2}}$ 
7. Perankingan Preferensi

Nilai preferensi untuk setiap alternatif $\left(V_{i}\right)$ adalah sebagai berikut:

$V_{i}=\frac{D_{i}^{-}}{D_{i}^{-}+D_{i}^{+}}$

Nilai $V_{i}$ terbesar mengindikasikan bahwa alternatif $A_{i}$ merupakan alternatif terbaik.

\subsection{Komputasi Graphical User Interface (GUI)}

Menurut Sugiharto (2006), matlab merupakan perangkat lunak yang cocok dipakai sebagai alat komputasi yang melibatkan penggunaan matriks dan vektor. GUIDE atau GUI builder merupakan sebuah Graphical User Interface (GUI) yang dibangun dengan obyek grafis seperti tombol (button), kotak teks, slider, sumbu (axes), maupun menu.

\section{METODOLOGI PENELITIAN}

\subsection{Jenis dan Sumber Data}

Pada penelitian ini jenis data yang digunakan adalah data primer. Pengumpulan data primer dilakukan dengan pengisian kuesioner untuk pembobotan kriteria dan penilaian perumahan. Teknik pengambilan sampel dalam penelitian ini menggunakan teknik probability sampling yaitu simple random sampling.

\subsection{Variabel Penelitian}

1. Variabel Alternatif $\left(A_{i}\right)$

Variabel alternatif dalam penelitian ini adalah 8 perumahan yang terdapat di Mijen Semarang.

2. Variabel Kriteria $\left(C_{i}\right)$

Variabel kriteria yang digunakan untuk menentukan perumahan terfavorit yaitu sebanyak 5 kriteria, antara lain harga, system pembayaran, spesifikasi bangunan, fasilitas perumahan dan lokasi. Seluruh kriteria tersebut dinilai dengan menggunakan skala penilaian antara 0 hingga 10 .

\section{ANALISIS DAN PEMBAHASAN}

\subsection{Penetuan Perumahan Terfavorit di Mijen Semarang Menggunakan Metode VIKOR}

Metode VIKOR merupakan salah satu metode MCDM yang memiliki prosedur perhitungan sederhana dengan pertimbangan kedekatan antar alternatif dengan solusi ideal. Langkah-langkah perhitungan dengan metode ini adalah sebagai berikut:

1) Pembuatan Matriks Keputusan $\operatorname{MCDM}(\boldsymbol{X})$

Tabel 1. Matriks Keputusan MCDM

\begin{tabular}{cccccc}
\hline \multirow{2}{*}{$\begin{array}{c}\text { Alternatif } \\
\text { Perumahan }\end{array}$} & \multicolumn{5}{c}{ Kriteria } \\
\cline { 2 - 6 } $\boldsymbol{C}_{\boldsymbol{1}}$ & $\boldsymbol{C}_{\boldsymbol{2}}$ & $\boldsymbol{C}_{\boldsymbol{3}}$ & $\boldsymbol{C}_{\boldsymbol{4}}$ & $\boldsymbol{C}_{\boldsymbol{5}}$ \\
\hline$A_{1}$ & 7,195 & 7,186 & 7,418 & 7,334 & 7,623 \\
$A_{2}$ & 7,398 & 7,295 & 7,569 & 8,093 & 6,992 \\
$A_{3}$ & 7,683 & 7,277 & 7,743 & 8,227 & 7,765 \\
$A_{4}$ & 6,893 & 7,048 & 7,415 & 7,874 & 7,580 \\
$A_{5}$ & 8,028 & 7,396 & 8,609 & 8,389 & 7,893 \\
$A_{6}$ & 6,263 & 6,993 & 7,624 & 7,969 & 7,579 \\
$A_{7}$ & 7,985 & 7,430 & 7,755 & 8,167 & 7,838 \\
$A_{8}$ & 6,585 & 6,724 & 7,538 & 7,832 & 7,593 \\
\hline
\end{tabular}


2) Penentuan Nilai Bobot Kriteria (w)

Rata-rata nilai kuesioner yang diperoleh adalah sebagai berikut:

$$
\begin{array}{lll}
u_{1}: 8,697 ; & u_{2}: 6,708 ; & u_{3}: 8,036 ; \\
u_{4}: 7,247 ; & u_{5}: 8,916 . &
\end{array}
$$

Syarat pembobotan dalam MCDM yaitu $\sum_{j=1}^{n} w_{j}=1$. Hasil dari perhitungan nilai bobot kriteria ditunjukkan pada Tabel 2.

Tabel 2. Nilai Bobot Kriteria

\begin{tabular}{ccccc}
\hline $\boldsymbol{w}_{\boldsymbol{1}}$ & $\boldsymbol{w}_{\mathbf{2}}$ & $\boldsymbol{w}_{\mathbf{3}}$ & $\boldsymbol{w}_{\mathbf{4}}$ & $\boldsymbol{w}_{\mathbf{5}}$ \\
\hline 0,2196 & 0,1694 & 0,2029 & 0,1830 & 0,2251 \\
\hline
\end{tabular}

3) Penentuan Matriks Keputusan Ternormalisasi $(\boldsymbol{N})$

Matriks keputusan ternormalisasi $(\boldsymbol{N})$ berisi nilai yang dihitung dengan rumus Persamaan (4). Tabel 3 menunjukkan hasil perhitungan elemen matriks ternormalisasi berdasarkan Persamaan (4).

Tabel 3. Matriks Keputusan Ternormalisasi (VIKOR)

\begin{tabular}{cccccc}
$\begin{array}{c}\text { Alternatif } \\
\text { Perumahan }\end{array}$ & $\boldsymbol{N}_{\boldsymbol{i 1}}$ & $\boldsymbol{N}_{\boldsymbol{i} \mathbf{2}}$ & $\boldsymbol{N}_{\boldsymbol{i 3}}$ & $\boldsymbol{N}_{\boldsymbol{i} \mathbf{}}$ & $\boldsymbol{N}_{\boldsymbol{i}}$ \\
\hline $\boldsymbol{A}_{\boldsymbol{1}}$ & 0,4890 & 0,3456 & 0,9975 & 1 & 0,2997 \\
$\boldsymbol{A}_{\boldsymbol{2}}$ & 0,3796 & 0,1912 & 0,8710 & 0,2806 & 1 \\
$\boldsymbol{A}_{\boldsymbol{3}}$ & 0,2125 & 0,2167 & 0,7253 & 0,1536 & 0,1421 \\
$\boldsymbol{A}_{\boldsymbol{4}}$ & 0,6714 & 0,5411 & 1 & 0,4882 & 0,3474 \\
$\boldsymbol{A}_{5}$ & 0 & 0,0482 & 0 & 0 & 0 \\
$\boldsymbol{A}_{\boldsymbol{6}}$ & 1 & 0,6190 & 0,8250 & 0,3981 & 0,3485 \\
$\boldsymbol{A}_{\boldsymbol{7}}$ & 0,0527 & 0 & 0,7152 & 0,2104 & 0,0610 \\
$\boldsymbol{A}_{\boldsymbol{8}}$ & 0,8459 & 1 & 0,8970 & 0,5280 & 0,3330 \\
\hline
\end{tabular}

4) Penentuan Matriks Keputusan Ternormalisasi Terbobot $(\boldsymbol{F})$

Rating bobot ternormalisasi $\left(\boldsymbol{F}_{\boldsymbol{i j}}\right)$ dihitung dengan rumus pada Persamaan (7).

Tabel 4. Matriks Keputusan Ternormalisasi Terbobot (VIKOR)

\begin{tabular}{cccccc}
$\begin{array}{c}\text { Alternatif } \\
\text { Perumahan }\end{array}$ & $\boldsymbol{F}_{\boldsymbol{i} \boldsymbol{1}}$ & $\boldsymbol{F}_{\boldsymbol{i} \boldsymbol{2}}$ & $\boldsymbol{F}_{\boldsymbol{i} \boldsymbol{3}}$ & $\boldsymbol{F}_{\boldsymbol{i} \boldsymbol{4}}$ & $\boldsymbol{F}_{\boldsymbol{i} \boldsymbol{5}}$ \\
\hline $\boldsymbol{A}_{\boldsymbol{1}}$ & 0,1074 & 0,0585 & 0,2024 & 0,1830 & 0,0675 \\
$\boldsymbol{A}_{\boldsymbol{2}}$ & 0,0834 & 0,0324 & 0,1768 & 0,0513 & 0,2251 \\
$\boldsymbol{A}_{\boldsymbol{3}}$ & 0,0467 & 0,0367 & 0,1472 & 0,0281 & 0,0320 \\
$\boldsymbol{A}_{\boldsymbol{4}}$ & 0,1474 & 0,0916 & 0,2029 & 0,0893 & 0,0782 \\
$\boldsymbol{A}_{\boldsymbol{5}}$ & 0 & 0,0082 & 0 & 0 & 0 \\
$\boldsymbol{A}_{\boldsymbol{6}}$ & 0,2196 & 0,1048 & 0,1674 & 0,0728 & 0,0785 \\
$\boldsymbol{A}_{\boldsymbol{7}}$ & 0,0116 & 0 & 0,1451 & 0,0385 & 0,0137 \\
$\boldsymbol{A}_{\boldsymbol{8}}$ & 0,1858 & 0,1693 & 0,1820 & 0,0966 & 0,0750 \\
\hline
\end{tabular}

5) Menghitung Utility Measures 
Utility measures dihitung menggunakan Persamaan (8) dan (9). Tabel 5 menunjukkan hasil perhitungan utility measures setiap alternatif. 
Tabel 5. Utility Measures (VIKOR)

\begin{tabular}{ccc}
$\begin{array}{c}\text { Alternatif } \\
\text { Perumahan }\end{array}$ & $\boldsymbol{S}_{\boldsymbol{i}}$ & $\boldsymbol{R}_{\boldsymbol{i}}$ \\
\hline $\boldsymbol{A}_{\boldsymbol{1}}$ & 0,6188 & 0,2024 \\
$\boldsymbol{A}_{\boldsymbol{2}}$ & 0,5690 & 0,2251 \\
$\boldsymbol{A}_{3}$ & 0,2906 & 0,1472 \\
$\boldsymbol{A}_{\boldsymbol{4}}$ & 0,6095 & 0,2029 \\
$\boldsymbol{A}_{\boldsymbol{5}}$ & 0,0082 & 0,0082 \\
$\boldsymbol{A}_{\boldsymbol{6}}$ & 0,6431 & 0,2196 \\
$\boldsymbol{A}_{\boldsymbol{7}}$ & 0,2090 & 0,1451 \\
$\boldsymbol{A}_{\boldsymbol{8}}$ & 0,7087 & 0,1858 \\
\hline
\end{tabular}

6) Perhitungan Nilai Preferensi $\left(\boldsymbol{Q}_{i}\right)$

Perhitungan preferensi setiap alternatif dicari menggunakan rumus indeks VIKOR $(\boldsymbol{Q})$ menggunakan Persamaan (10). Hasil nilai preferensi pada 8 alternatif perumahan ditunjukkan pada Tabel 6.

Tabel 6. Nilai Indeks VIKOR

\begin{tabular}{cc}
\hline $\begin{array}{c}\text { Alternatif } \\
\text { Perumahan }\end{array}$ & $\boldsymbol{Q}_{\boldsymbol{i}}$ \\
\hline$A_{1}$ & 0,8834 \\
$A_{2}$ & 0,9003 \\
$A_{3}$ & 0,5220 \\
$A_{4}$ & 0,8780 \\
$A_{5}$ & 0 \\
$A_{6}$ & 0,9404 \\
$A_{7}$ & 0,4590 \\
$A_{8}$ & 0,9092 \\
\hline
\end{tabular}

7) Penentuan Perumahan Terfavorit di Mijen Semarang

Nilai preferensi untuk setiap alternatif kemudian diurutkan dari yang paling rendah hingga paling tinggi. Tabel 7 menunjukkan hasil perangkingan alternatif menggunakan metode VIKOR.

Tabel 7. Urutan Preferensi (VIKOR)

\begin{tabular}{clc}
\hline Peringkat & $\begin{array}{c}\text { Alternatif } \\
\text { Perumahan }\end{array}$ & $\boldsymbol{Q}_{\boldsymbol{i}}$ \\
\hline 1 & $A_{5}$ & 0 \\
2 & $A_{7}$ & 0,4590 \\
3 & $A_{3}$ & 0,5220 \\
4 & $A_{4}$ & 0,8780 \\
5 & $A_{1}$ & 0,8834 \\
6 & $A_{2}$ & 0,9003 \\
7 & $A_{8}$ & 0,9092
\end{tabular}


$8 \quad A_{6} \quad 0,9404$

\subsection{Penetuan Perumahan Terfavorit di Mijen Semarang Menggunakan Metode TOPSIS}

Metode TOPSIS didasarkan pada konsep dimana alternatif terpilih yang terbaik tidak hanya memiliki jarak terpendek dari solusi ideal positif, namun juga memiliki jarak terpanjang dari solusi ideal negatif (Kusumadewi, 2006).

Langkah-langkah perhitungan dengan metode ini adalah sebagai berikut:

1) Penentuan Matriks Keputusan Ternormalisasi $(\boldsymbol{P})$

Penentuan nilai rating kinerja ternomalisasi $\left(p_{i j}\right)$ dihitung dengan rumus seperti pada Persamaan (11). Hasil matriks $\boldsymbol{P}$ yang ditunjukkan pada Tabel 8.

Tabel 8. Matriks Keputusan Ternormalisasi (TOPSIS)

\begin{tabular}{|c|c|c|c|c|c|}
\hline $\begin{array}{l}\text { Alternatif } \\
\text { Perumahan }\end{array}$ & $p_{i l}$ & $p_{i 2}$ & $p_{i 3}$ & $p_{i 4}$ & $p_{i 5}$ \\
\hline$A_{1}$ & 0,3495 & 0,3542 & 0,3398 & 0,3245 & 0,3540 \\
\hline$A_{2}$ & 0,3589 & 0,3596 & 0,3468 & 0,3581 & 0,3247 \\
\hline$A_{3}$ & 0,3733 & 0,3587 & 0,3547 & 0,3640 & 0,3606 \\
\hline$A_{4}$ & 0,3338 & 0,3474 & 0,3397 & 0,3484 & 0,3521 \\
\hline$A_{5}$ & 0,3916 & 0,3646 & 0,3944 & 0,3711 & 0,3666 \\
\hline$A_{6}$ & 0,3055 & 0,3447 & 0,3493 & 0,3526 & 0,3520 \\
\hline$A_{7}$ & 0,3871 & 0,3663 & 0,3553 & 0,3613 & 0,3640 \\
\hline$A_{8}$ & 0,3188 & 0,3315 & 0,3453 & 0,3465 & 0,3527 \\
\hline
\end{tabular}

2) Penentuan Matriks Keputusan Ternormalisasi Terbobot $(\boldsymbol{Y})$

Rating bobot ternormalisasi $\left(y_{i j}\right)$ dihitung dengan rumus pada Persamaan (12). Tabel 9 menunjukkan matriks $\boldsymbol{Y}$ yang merupakan matriks keputusan ternormalisasi terbobot.

Tabel 9. Matriks Keputusan Ternormalisasi Terbobot (TOPSIS)

\begin{tabular}{|c|c|c|c|c|c|}
\hline $\begin{array}{l}\text { Alternatif } \\
\text { Perumahan }\end{array}$ & $y_{i 1}$ & $y_{i 2}$ & $y_{i 3}$ & $y_{i 4}$ & $y_{i 5}$ \\
\hline$A_{1}$ & 0,0768 & 0,0600 & 0,0690 & 0,0594 & 0,0797 \\
\hline$A_{2}$ & 0,0788 & 0,0609 & 0,0704 & 0,0655 & 0,0731 \\
\hline$A_{3}$ & 0,0820 & 0,0608 & 0,0720 & 0,0666 & 0,0812 \\
\hline$A_{4}$ & 0,0733 & 0,0588 & 0,0689 & 0,0637 & 0,0793 \\
\hline$A_{5}$ & 0,0860 & 0,0617 & 0,0800 & 0,0679 & 0,0825 \\
\hline$A_{6}$ & 0,0671 & 0,0584 & 0,0709 & 0,0645 & 0,0793 \\
\hline$A_{7}$ & 0,0850 & 0,0620 & 0,0721 & 0,0661 & 0,0820 \\
\hline$A_{8}$ & 0,0700 & 0,0561 & 0,0701 & 0,0634 & 0,0794 \\
\hline
\end{tabular}

3) Penentuan Matriks Solusi Ideal Positif $\left(A^{+}\right)$dan Matriks Solusi Ideal Negatif $\left(A^{-}\right)$ 
Hasil perhitungan solusi ideal positif berdasarkan Persamaan (13) adalah sebagai berikut:

$A^{+}=\{0,0860 ; 0,0620 ; 0,0800 ; 0,0679 ; 0,0825\}$ 

berikut:

Hasil perhitungan solusi ideal negatif berdasarkan Persamaan (14) adalah sebagai $A^{-}=\{0,0671 ; 0,0561 ; 0,0689 ; 0,0594 ; 0,0731\}$

4) Penentuan Jarak antara Nilai Setiap Alternatif dengan Matriks Solusi Ideal Positif dan Matriks Solusi Ideal Negatif

Jarak antara alternatif $A_{i}$ dengan solusi ideal positif dirumuskan seperti pada Persamaan (17) dan jarak antara alternatif $A_{i}$ dengan solusi ideal negatif dirumuskan seperti pada Persamaan (18). Hasil dari jarak tiap alternatif dengan solusi ideal ditunjukkan pada Tabel 10.

Tabel 10. Jarak antara Nilai Setiap Alternatif dengan Matriks Solusi Ideal Positif dan Matriks Solusi Ideal Negatif (TOPSIS)

\begin{tabular}{ccc}
$\begin{array}{c}\text { Alternatif } \\
\text { Perumahan }\end{array}$ & $\boldsymbol{D}^{+}$ & $\boldsymbol{D}_{\boldsymbol{i}}{ }^{-}$ \\
\hline $\boldsymbol{A}_{\boldsymbol{1}}$ & 0,0171 & 0,0123 \\
$\boldsymbol{A}_{\boldsymbol{2}}$ & 0,0155 & 0,0141 \\
$\boldsymbol{A}_{3}$ & 0,0093 & 0,0192 \\
$\boldsymbol{A}_{\boldsymbol{4}}$ & 0,0180 & 0,0101 \\
$\boldsymbol{A}_{\boldsymbol{5}}$ & 0,0003 & 0,0260 \\
$\boldsymbol{A}_{\boldsymbol{6}}$ & 0,0218 & 0,0085 \\
$\boldsymbol{A}_{\boldsymbol{7}}$ & 0,0082 & 0,0221 \\
$\boldsymbol{A}_{\boldsymbol{8}}$ & 0,0205 & 0,0081 \\
\hline
\end{tabular}

5) Perhitungan Nilai Preferensi $\left(V_{i}\right)$

Nilai preferensi untuk setiap alternatif $\left(A_{i}\right)$ diperoleh dari hasil perhitungan menggunakan Persamaan (19). Hasil nilai preferensi pada 8 alternatif perumahan ditunjukkan pada Tabel 11.

Tabel 11. Nilai Preferensi (TOPSIS)

\begin{tabular}{cc}
\hline $\begin{array}{c}\text { Alternatif } \\
\text { Perumahan }\end{array}$ & $\mathbf{V}_{\mathbf{i}}$ \\
\hline$A_{1}$ & 0,4185 \\
$A_{2}$ & 0,4769 \\
$A_{3}$ & 0,6746 \\
$A_{4}$ & 0,3609 \\
$A_{5}$ & 0,9892 \\
$A_{6}$ & 0,2811 \\
$A_{7}$ & 0,7290 \\
$A_{8}$ & 0,2832 \\
\hline
\end{tabular}

6) Penentuan Perumahan Terfavorit di Mijen Semarang

Nilai preferensi untuk setiap alternatif kemudian diurutkan dari yang paling tinggi hingga paling rendah. Hasil nilai preferensi pada 8 alternatif perumahan ditunjukkan pada Tabel 12. 
Tabel 12. Urutan Preferensi (TOPSIS)

\begin{tabular}{clc}
\hline Peringkat & $\begin{array}{c}\text { Alternatif } \\
\text { Perumahan }\end{array}$ & $\boldsymbol{V}_{\boldsymbol{i}}$ \\
\hline 1 & $A_{5}$ & 0,9892 \\
2 & $A_{7}$ & 0,7290 \\
3 & $A_{3}$ & 0,6746 \\
4 & $A_{2}$ & 0,4769 \\
5 & $A_{1}$ & 0,4185 \\
6 & $A_{4}$ & 0,3609 \\
7 & $A_{8}$ & 0,2832 \\
8 & $A_{6}$ & 0,2811 \\
\hline
\end{tabular}

\subsection{GUI Matlab Metode VIKOR dan TOPSIS}

a. Layar Utama

Tampilan pada Gambar 1 merupakan tampilan layar utama. Kemudian klik tombol "MULAI" untuk terhubung ke layar kedua.

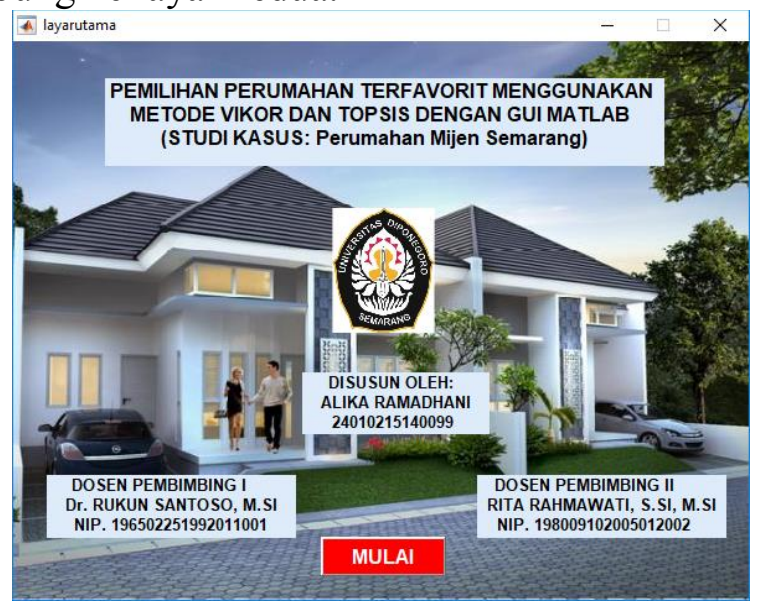

b. Layar Kedua

Gambar 1. Tampilan Layar Utama

Layar kedua berisikan alternatif dan kriteria penilaian. Selanjutnya klik tombol "MULAI ANALISIS" untuk terhubung pada layar ketiga dan memulai analisis.

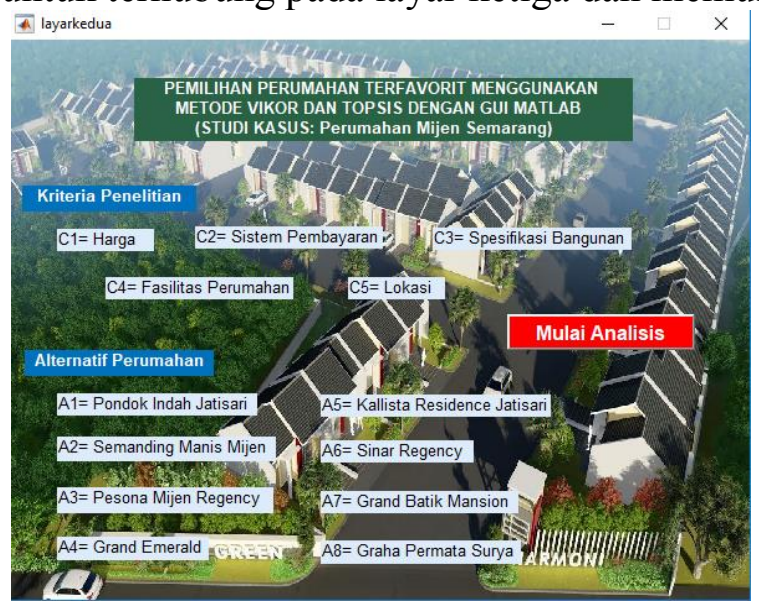

Gambar 2. Tampilan Layar Kedua 


\section{c. Layar Ketiga}

Layar ketiga berisikan analisis perhitungan metode VIKOR dan TOPSIS. Klik "ULANG" untuk mengulang dan menghapus hasil perhitungan. Klik "KELUAR" untuk mengakhiri perhitungan.

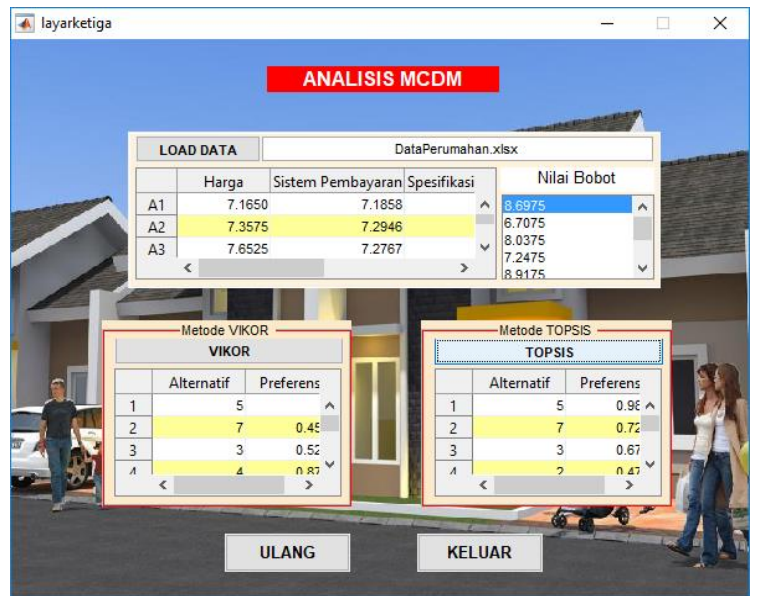

Gambar 3. Hasil Perhitungan VIKOR dan TOPSIS

\section{KESIMPULAN}

Penggunaan metode MCDM VIKOR dan TOPSIS pada pemilihan perumahan terfavorit memberikan hasil bahwa alternatif perumahan $\mathrm{A}_{5}$ merupakan perumahan terfavorit di Mijen Semarang. Penentuan bobot untuk masing-masing kriteria diperoleh dari kuesioner. Nilai bobot terbesar dalam penelitian ini adalah kriteria lokasi perumahan sebesar 0,2251, sedangkan nilai bobot terkecil dalam penelitian ini adalah sistem pembayaran sebesar 0,1694 . Hal ini berarti kriteria lokasi perumahan merupakan kriteria yang memiliki pengaruh terbesar dalam menentukan perumahan terfavorit di Mijen Semarang dan kriteria sistem pembayaran merupakan kriteria yang memiliki pengaruh terkecil dalam menentukan perumahan terfavorit di Mijen Semarang.

Komputasi dengan GUI Matlab memiliki hasil yang sesuai dengan perhitungan matematis Ms. Excel. GUI Matlab yang dibentuk memiliki keunggulan dalam kemudahan dan kecepatan dalam komputasi. GUI Matlab mampu menampilkan langkah yang sistematis, mudah dipahami dan secara otomatis mampu melakukan perhitungan dengan cepat. Sehingga pemakai pemula dapat dengan mudah melakukan komputasi MCDM VIKOR dan TOPSIS.

\section{DAFTAR PUSTAKA}

Kusumadewi, S., Hartati, S., Harjoko, A., dan Wardoyo, R. 2006. Fuzzy Multi-Attribute Decision Making (FUZZY MADM). Yogyakarta: Graha Ilmu.

Mukono, H.J. 2000. Prinsip Dasar Kesehatan Lingkungan. Universitas Airlangga: Surabaya.

Opricovic, S. dan Tzeng, G.H. 2004. Compromise Solution by MCDM Methods: A Comparative Analysis of VIKOR and TOPSIS. European Journal of Operational Research, 156(2), 445-455.

Sugiharto, A. 2006. Pemrograman GUI dengan MATLAB . Yogyakarta: Andi OFFSET.

Turban, E. 1990. Decision Support and Expert System: Management Support System. Mac Millan Pub. Co., New York. 